\title{
International Village Revitalization Experience and Its Enlightenment to China
}

\author{
Guiyan Zhao, Wei Wang \\ College of Economics And Management, Heilongjiang Bayi Agricultural University, Daqing, China, 163319
}

Keywords: Rural Rejuvenation, Industrial Integration, Experience and Reference, Agricultural and Rural Modernization

\begin{abstract}
The "Opinions of the Central Committee of the Communist Party of China and the State Council on Implementing the Strategy for Rural Rejuvenation" clearly states that the main goal of China's "agriculture,rural areas, and farmers is to adhere to the priority development of agriculture and rural areas,in accordance with the prosperity of industries,ecological livability,rural civilization,effective governance,and a wealthy life.General requirements,adhere to the priority development of agriculture and rural areas, and accelerate the modernization of agriculture and rural areas.
\end{abstract}

\section{Introduction}

In terms of foreign experience, [1]Ian Knowd (2006) researched the relationship between tourism, community and economic development in the suburbs of Sydney, Australia. Analyzing the interactive relationship between farmers and tourists poses new challenges to farmers' production, marketing and services. The study found that the problems of small-scale and irregular management of suburban tourism, and the conflict between the development of rural tourism and land use, put forward the focus on the sustainable development of tourism. [2]Dong Jie(2013) introduced Japan's agricultural support policy, and proposed that China can learn from Japan's sound agricultural policy, attach importance to the role of agricultural industry associations, improve agricultural cooperation organizations, and use Japan's agricultural trade support policy to learn,China should continue to improve agricultural imports and exports.Subsidy policy; Cai Xin,Chen Yongfu, etc. [3] analyzed and discussed the evolution,development trend, and operation mode of Japan's agricultural support policies,and should guide farmers to organize operations, orderly expand the scale of farmers' operations, and digest the surplus agricultural labor on the spot Xu Shuyao[4](2016) analyzed that China should learn from Japan's agricultural support policy and continue to adjust the internal structure of agricultural support. The direction of agricultural support should be based on market regulation. The support methods of agricultural products should be diversified. Agricultural products with large demand space should be given key support; Qian Xiaoping, Yin Changbin, etc. (2016)[5] analyzed the agricultural environmental support policies of Japan and Europe and the United States, Japan established an environmentally-friendly agricultural development incentive mechanism, and Europe and the United States and other countries established good agricultural 
practices. By promoting the health of eco-agricultural systems Comprehensive development and promotion of sustainable agricultural development; [6]Liu Zhen (2018) explored the experience and practice of rural construction in Japan from the perspective of urban-rural integration, and proposed a path for rural revitalization that China can learn from: First, implement the strategy of industrial development of agriculture. The city nurtures the countryside. Secondly, it implements the strategy of ecologically developing agriculture to meet the ecological needs of urban residents. Thirdly, it strengthens the combination of cultural construction and grass-roots governance to achieve the coordinated development of urban and rural areas. Finally, it promotes the integration of urban and rural areas and realizes the fundamental goal of common prosperity for the people.

To sum up, there is more literature on the experience of foreign rural revitalization in the existing literature, and less literature on Chinese practice and its inspiration to China; Japan, South Korea, Britain, Germany, the Netherlands, the United States and other agricultural developed countries are promoting rural revival. Exploration and practice in this area have achieved significant results. Combining advanced experiences and practices has certain reference value for the implementation of rural revitalization strategies in China. Analyzing the evolution process of rural revitalization strategies in agricultural developed countries is important for China's implementation of rural revival strategies.

\section{International Experience in Rural Revitalization}

\subsection{Japan Builds a Complete Industrial Chain Model and Implements "Six Industrialization" of Agriculture}

Since the 21st century, the Japanese government has begun to develop the "sixth industry", that is, the effective integration of agricultural product production, food processing and fertilizer production, agricultural product distribution and information services, and the integration of production, sales, and sales services has both increased the added value of agricultural products and increased It has boosted farmers' income, rejuvenated the agricultural and rural economy, and established a low-carbon, highly efficient modern agricultural industrial system.

Japan mainly builds four types of industrial chain models, one is the integrated production and sales model of agricultural products, which directly processes and sells at the place of production, or promotes the front store and back factory model; the second is the direct sales model of agricultural products, which sets up direct sales specialty stores to sell local agricultural products and Processed agricultural products; the third is the comprehensive development model of agricultural product production and sales, the comprehensive development of agricultural product production and sales, and catering; the fourth is the development of tourism agriculture, that is, the "one village, one product" model. It is a new type of agricultural business model that combines agricultural industry and rural landscapes to attract tourists for sightseeing, leisure and vacation, develops agricultural leading products with regional characteristics and distinct advantages, and promotes farmers' income and agricultural development. 


\subsection{South Korea Implements the "New Village Movement" to Give Full Play to the Role of}

Farmers

The Korean government has implemented the "New Village Movement" since the 1970s. The "New Village Movement" is divided into four phases. The first phase was the phase of building rural infrastructure from 1971 to 1973, that is, the phase of improving the living environment of rural residents. The government provided the residents of 33,000 administrative villages with free materials such as cement and steel to improve the living environment, and implemented rural infrastructure construction by widening roads,building sewage systems, and constructing fences; the second stage was 1974-1976 is the stage of rural modernization construction, that is, the stage of improving the living environment and the quality of life. It will improve the level of rural infrastructure through the construction of villagers' halls, reading rooms, sports fields, etc., and adjust the crop planting structure, develop animal husbandry, and popularize high-yield "unified rice". The promotion of agricultural technology innovation knowledge and other methods focused on increasing farmers' income, and initially realized the modernization of agriculture and rural areas; the third stage was the stage of agricultural mechanization and protection of nature from 1977 to 1980, that is, the stage of improving the living environment and the quality of life. Promote agricultural productivity, including greening projects The government has realized land water security by developing water resources and harnessing river basins. The fourth stage is the stage from 1981 to the present in order to give play to the role of farmers as the mainstay of rural rejuvenation, that is, the stage of insisting on farmers to participate in the mainstay of rural rejuvenation. Fully mobilize the subjective initiative of peasants to participate in the "New Village Movement", begin to focus on spiritual civilization construction, democracy and law construction, public morality construction, establish and improve civil organizations of the "New Village Movement", improve the knowledge and cultural level of rural residents, and cultivate the independence of rural residents Self-improvement.

The United Kingdom uses the "empowerment theory" to play the role of the governance subject from the aspects of individual empowerment, organizational empowerment and community empowerment.

In the process of rural revitalization in the United Kingdom, Britain used the theory of empowerment to promote the development of rural revitalization. The core idea is: starting from the incentive mechanism, giving individuals, organizations, and communities different units of empowerment, thereby stimulating the villagers' self-consciousness and obtaining the necessary This kind of rights and resources can effectively increase farmers 'income, protect farmers' legal rights, give play to the role of governance,and promote the development of rural society.

Individual empowerment means empowering the people, giving play to the role of farmers as the main force for the revitalization of the countryside, strengthening farmers' sense of ownership, and exerting self-management and self-government capabilities; Organizational empowerment refers to the assistance of various social and government organizations, Use of organizational resources to empower and empower non-authorized individuals, give full play to the ability of organizational resources to expand the role, and mobilize individuals' enthusiasm for rural rejuvenation, such as the British National Trust and the British Rural Protection Movement, effectively promoting the construction of rural ecological culture; Community empowerment refers to empowerment through 
cohesion of community social organizations and improvement of the community's social system, to activate the community's autonomy function, and to make the community a backbone force for rural revitalization. Since 1990, Britain has implemented a major ministerial reform, transferring some public service responsibilities to the operation of social forces, which has not only improved the efficiency of government governance, but also reduced the cost of governance. It has provided legal services for social forces through community empowerment channel.

\section{International Experience and its Enlightenment on the Implementation of Rural Revitalization in China}

Foreign studies on rural revitalization are based on the actual situation in the country. From a practical perspective, they pursue rural planning and construction models suitable for local characteristics. Countries in the actual practice have adopted different entry points to develop and improve rural revitalization and construction paths. Mode selection. Therefore, China's rural rejuvenation and construction should learn from the world's rural construction experience and the typical cases of China's beautiful countryside, carry out reforms and innovations in rural construction, and constantly explore plans suitable for China's rural rejuvenation and construction. Through a comparative analysis of the experience of rural construction in Japan, South Korea, the United Kingdom, Germany, the Netherlands, the United States, and China, we can learn from the following aspects in rural construction in China.

\subsection{Give Play to the Leading Role of the Government}

Whether it is the "one village and one product" in Japan, the "New Village Movement" in South Korea, the "Village Renewal" plan in Germany, or the "Agricultural Land Consolidation" plan in the Netherlands, all are initiated by the government. The government plays a guiding role in rural revitalization. In accordance with different national conditions, governments of all countries should give full play to the government's guiding role in macro-control and legislative protection,and formulate specific rural revitalization implementation plans. The United States has formulated and improved relevant laws for rural rejuvenation,such as the "Agricultural Adjustment Act", "Agricultural Law", "New Agriculture Act 2014", "Agricultural Promotion Act 2018", etc. These agricultural bills focus on how to guide and support rural villages. Development, how to achieve sustainable development of agriculture and rural areas, regulate the construction of livable and suitable living areas in rural areas, the prosperity of a diversified economy in rural areas, the environmental protection of rural resources, and the construction of rural Internet, etc. The basic status of agriculture. According to the needs of different stages of agricultural and rural development in Japan, Japan has revised and improved agricultural laws and regulations such as the "Agricultural Land Law" and "Agricultural Basic Law", emphasizing the basic concept of "rural rejuvenation" and clarifying that it is necessary to use the secondary and tertiary industries to enhance the added value of agricultural products In addition, it is necessary to build a tourism and cultural industry system with rural characteristics to effectively promote grain production, farmers' income, and agricultural efficiency.

Foreign experience shows that it provides a development reference model for the rural revitalization of our country. The Chinese government must introduce corresponding policies and 
measures in the process of rural revitalization and construction, and absorb more social resources to participate in rural construction. In opening up financing channels for the construction of beautiful rural areas, the government can increase financial subsidies to private enterprises, tax and fee concessions and other methods to attract more enterprises to participate in the operation of rural industries and stimulate the endogenous driving force for the development of rural industries. The government must integrate resources in the construction of a beautiful countryside, so as to form a joint force between the government and enterprises and social organizations. Provide full funding, policy and technical support. On each project of rural revitalization and construction, the government should adopt a "one matter, one discussion" approach, and make specific solutions for each issue. In the process of rural construction, the government must also make the market mechanism work, and adopt the "who invests and benefits" approach to construct operational projects.

\subsection{Clarify the Subjective Status of Farmers}

Japan's "village-making movement" has a certain endogenous and spontaneous nature, and fully played the main role of villagers. The Japanese government did not provide financial support in the "village-making movement", but only provided technical and policy guarantees. This "village-making movement" fully reflects the unity of the people and the desire to realize rural rejuvenation. After this movement, the gap between urban and rural areas in Japan has narrowed significantly, and the people's income has increased significantly, greatly stimulating diversified projects such as rural tourism and culture construction. In the rural rejuvenation, the United Kingdom gave full play to the role of the peasant's main force and empowered the people, reflecting the peasant master consciousness and clarifying that peasants are the main body and important beneficiaries of agricultural and rural development.

International experience shows that rural revitalization must clarify the main role of farmers. Farmers are indispensable participants in rural revitalization. China must adhere to the status of farmers and beneficiaries when implementing rural revitalization strategies. The prerequisite for rural revitalization is to comply with the needs of millions of farmers. The key to life's longing for agricultural and rural economic development lies in the people. Farmers fully understand their needs, let farmers play the leading role in rural rejuvenation, participate in the construction planning of rural development, and clarify their role in rural rejuvenation. We must fully respect the wishes of the majority of farmers. To stimulate the creativity and initiative of the majority of farmers, enable farmers to take on the important responsibility of rural rejuvenation, activate the endogenous power of rural rejuvenation, promote the integration of urban and rural development, and make the majority of farmers have a sense of gain, happiness, and security.

\subsection{Focus on Infrastructure Construction}

South Korea, The United States, The Netherlands, and France all attach great importance to and improve the construction of agricultural infrastructure. For example, France financed the repair of residential buildings, the repair of rural roads, and the planning of bicycle lanes. South Korea has expanded roads, built sewage systems, and built fences. Convenient and solid infrastructure provides a strong guarantee for the revitalization of the countryside, and plays an important role in 
promoting the development of agricultural leading industries, increasing farmers' income and becoming rich, and improving the happiness index. Foreign experience shows that the construction of rural infrastructure must fully meet the main needs of farmers, and the improvement of public service systems must meet the needs of rural industrial development, improve farmers' participation and decision-making initiative, improve the level of infrastructure democratization, and effectively utilize infrastructure in agriculture. Support and guarantee role in modernization.

Foreign rural communities generally have cultural infrastructure, schools, museums, parks, hospitals, public toilets, networks, transportation and other community infrastructure to meet the basic needs of residents. Many villages have also built garbage treatment ponds and sewage treatment plants. Pollution treatment facilities and facilities also have sports fields for residents to exercise. Therefore, the key issue in implementing the strategic plan for rural revitalization is to focus on infrastructure construction and promote equalization of urban and rural public services.

\subsection{Implementation of Integrated Development of Rural Industries}

Japan, South Korea, The Netherlands, France and other countries have formed mature models in the long-term development of agricultural and rural practices, such as the "six industrialization" of Japan, the "sixth industrialization of agriculture" in South Korea, and the agricultural industry in the Netherlands"Chain", France's "rural tourism", etc. Foreign experience shows that, from the perspective of the industrial chain, China's agricultural products should establish a complete industrial chain, so that all links of production, sales and marketing are in an integrated state, form economies of scale, have strong processing and transformation capabilities, and can effectively increase the added value of agricultural products. China should also continue to support industrial chain extension, industry crossover, and industry integration through supporting support policies, combining its own location advantages, starting from the dominant leading industries, promoting the integration of leading industries, and strengthening agriculture and the rural economy.

Developed countries, such as the United Kingdom, the United States, South Korea, and France, attach great importance to industrial integration and development, and especially focus on the development of rural tourism.Leisure and wellness, tourism marketing "model, Japan's "one village, one product" model. Foreign experience shows that in rural planning, we should attach importance to the protection of natural and human resources, adhere to the concept of ecological economy, develop leisure tourism resources, promote the development of leisure agriculture, turn the countryside into an agricultural tourism complex, and promote the diversified development of rural industries. To improve the living environment and income of rural residents with rural tourism projects. Drawing on foreign experience, due to the profound historical and cultural accumulation and good humanistic foundation of Chinese villages, the upgrade of rural tourism construction has huge room for development. Therefore, the first step in the upgrade of China's rural tourism industry is to do a good job of cultural promotion and protection, to better integrate rural culture and rural tourism, and to provide consumers with cultural experience activities with unique rural customs. 


\section{Acknowledgment}

Daqing City Philosophy and Social Science Planning Research Project (Research on the Construction of Evaluation Index System for Rural Revitalization in Daqing City )

\section{References}

[1] Ian Knowd. Tourism as a Mechanism for Farm Survival. Journal of Sustainable Tourism, 2006, 14(1): 24-42.

[2] Dong Jie. Japan's agricultural support policy and Its Enlightenment to China. Japan studies, 2013, (1): 41-44.

[3] Cai Xin, Chen Yongfu, Han Xinru, et al. The latest trend and Enlightenment of Japan's agricultural support policy. China's agricultural resources and regionalization, 2016, 37 (7): 45-53.

[4] Xu Shuyao. Japanese agricultural support level and policy based on OECD. World agriculture, 2016, (10): 115-120.

[5] Qian Xiaoping, Yin Changbin, Fang Linna. Enlightenment of agricultural environment support policies in Japan and Europe and America on China. China's agricultural resources and regionalization, 2016, 37 (7): 35-44.

[6] Liu Zhen. Analysis of the path of Rural Revitalization from the perspective of urban-rural integration-based on the practice and experience of rural construction in Japan. People's forum academic frontier, 2018, 148 (12): 78-81. 